\title{
CAPAS TERCIADAS Y ESPADAS DESENVAINADAS EN ALGUNAS COMEDIAS DE CALDERÓN
}

\author{
Nieves Rodríguez Valle \\ Centro de Estudios Lingüísticos y Literarios \\ El Colegio de México A. C. \\ Camino al Ajusco No. 20 \\ Col. Pedregal de Sta. Teresa \\ C.P. 10740 \\ México, D.F. \\ nievesrv@yahoo.com.mx
}

[Anuario calderoniano (ISSN: 1888-8046), 6, 2013, pp. 211-228]

\begin{abstract}
Espada amor en rigor
es: luego, desenvainada,

si no hay burlas con la espada, no hay burlas con el amor. ${ }^{1}$
\end{abstract}

Así como afirma don Alonso que, una vez desenvainada, no hay burlas con la espada, Calderón, afila la pluma y en las comedias de "capa y espada», donde el género pide galanes y damas que se escon-

${ }^{1}$ Calderón, No hay burlas con el amor, III, vv. 2612-2615. 
dan y cubran, equívocos, celos y riñas con espadas ${ }^{2}$, convierte, a estas últimas en lenguaje, más que escénico, literario y poético, y utiliza los elementos simbólicos del imaginario popular y culto del campo semántico de las capas y de las espadas para construir con ellos escenas y ambientes. De este modo, capas y espadas son elementos reales que aparecen en escena, pero, a la vez, están presentes en el lenguaje metafórico.

El uso de capas y espadas, en las comedias del género al que la tradición bautizó con ellas ${ }^{3}$, aporta a la coherencia genérica de la utilización de un vestuario que, según ha estudiado Eduardo ForastieriBraschi, era la indumentaria común de la calle, que contaba con la aprobación cultural colectiva. Así, actores y público compartían códigos y reafirmaban valores: «las secuencias del despliegue oportuno de las capas, en el momento justo en que este coincide con nuestras expectativas, delatan una modalidad de género por la que aplaudimos al galán de comedias y al torero. [...] representan los ritos culturales de la reafirmación colectiva por el aplauso en los foros de la plaza o del corral» $»^{4}$.

Respetando el género, vemos las capas muy bien puestas en los galanes, pues como caballeros ya nobles, ya establecidos o pretendientes deben portarla dignamente cuando van de camino; con la misma dignidad deben terciarla ${ }^{5}$ para poder reñir en el momento que se les exija; la capa servirá también, en el juego escénico, para embozarse durante sus lances amorosos. Los galanes no la tienen caída (no va decayendo ni su hacienda ni su crédito) ${ }^{6}$ ni al hombro (no son traba-

2 Estrictamente serían «riñas», pues un «duelo», implicaría que los combatientes determinaran un lugar y tiempo específico para la pelea, en cambio, lo que sucede en las comedias de capa y espada son riñas al calor del momento, en un lugar público, en donde los galanes se hacen de palabras y sacan las espadas. Los duelos, a pesar de haber sido prohibidos por el Concilio de Trento en 1563, siguieron practicándose en España hasta mediados del siglo XVII; Calderón trata el tema en El postrer duelo de España. Véase la «Introducción» que realiza Guy Rossetti a dicha obra.

${ }^{3}$ Para la definición del género véase a Arellano, Convención y recepción. Estudios sobre el teatro del Siglo de Oro, 1999.

${ }^{4}$ Forastieri-Braschi, «Secuencias de capa y espada: escondidos y tapadas en Casa con dos puertas", 1981, p. 445.

5 Terciar: 'poner algo atravesado diagonalmente o al sesgo, o ladearlo' (DRAE).

${ }^{6}$ Para la tradición la "capa caída» significa «el que va descaído, perdidoso y vencido, y del que va a menos en su hacienda y trato, y anda fallido y en quiebra» 
jadores y sí tienen hacienda) ${ }^{7}$. La capa, "vestidura que se pone sobre todas las demás» ${ }^{8}$ representan la riqueza y la nobleza ${ }^{9}$, y así veremos en estas comedias "capa larga de hombres ancianos [y] capa corta de mozos y galanes» ${ }^{10}$. Los caballeros no pueden estar sin ella, como nos lo dice Marcela, en Casa con dos puertas, mala es de guardar:

$\begin{array}{ll}\text { Marcela } & \text { Hablarte ya claramente; } \\ \text { que puesto que a esta hora falta } \\ \text { mi hermano, ya no vendrá, } \\ \text { hasta que le lleven capa } \\ \text { y valona, o sea de noche. }\end{array}$

$$
\text { (II, vv. 1849-1853) }{ }^{11}
$$

(Correas, Vocabulario de refranes y frases proverbiales [1627], p. 401). También se dice «del que ha ido perdiendo hacienda y crédito" (Covarrubias, Tesoro de la lengua castellana o española [1611], en adelante: Cov.). Varios son los refranes o las frases proverbiales que tratan de las capas caídas: "Ir de capa caída: Por ir en menoscabo» (Correas, p. 979); «No dejarse caer la capa: Por: ser hombre de brío y pecho. Al contrario, "Dejarse caer la capa", por: no ser para defender su persona como hombre» (Correas, p. 1011); «No se deja caer la capa. No me dejo caer la capa: Por valor» (Correas, p. 1022); «Yo no me dejo caer la capa: Soy hombre que sé defender mi partido» (Correas, p. 1109).

7 «Ser hombre de poca suerte, caminador o trabajador» (Cov.); como también registra Correas: «Hombre con la capa al hombro: Por: hombre sin hacienda ni oficio» (Correas, p. 976).

${ }^{8}$ Cov, s. $v$.

${ }^{9}$ Así lo recoge el refranero, como símbolo del poder económico, de la estratificación social. Correas registra: «Al hombre pobre, capa de pardo y mesa de roble, taza de plata, cántaro y olla de cobre» (p. 59); «Tiene más remiendos que capa de pobre» (p. 773); «Fiesta de tres capas. Fiesta doble: por muy solemne» (p. 954); «Capa azul, ni honra vivos en salud, ni muertos en ataúd" (p. 154); "Capa negra y cofradía, no puede ser cada día» (p. 155); "Quien tiene capa, luego escapa; quien chapirón, o escapa, o non» (p. 697); incluso, el refranero juzga que dinero y virtud no van juntos: «Abernuncio, Satanás. - Mala capa llevarás: Es decir: que el que quiere vivir bien con mucha conciencia, vivirá pobre» (p. 41); «Los hijos de buenos, capas son de duelos: Que sufren y pasan por todo, y ayudan a otros» (p. 472).

10 Cov, s. $v$.

11 Todas las citas a Casa con dos puertas, mala es de guardar corresponden a la edición de A. Rey Hazas y F. Sevilla Arrollo, 1989. 
Es que la noche es la gran capa que nos cubre y nos encubre ${ }^{12}$. Si la capa, escénicamente, como hemos mencionado, se presta para los juegos de embozados que permite los equívocos y las personalidades disimuladas, necesarios para que se cumpla el género, todo a su alrededor se contagia ${ }^{13}$. Los embozos serán utilizados metafóricamente por Calderón, pues, incluso el cielo y el sol, como caballeros, se embozan y así se disfrazan, como afirma don Félix en Casa con dos puertas, mala es de guardar:

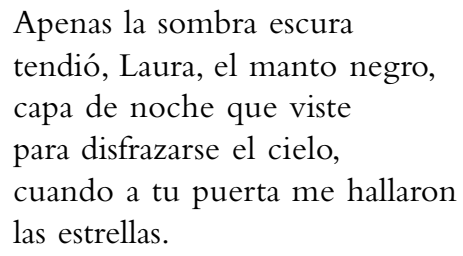

(II, vv. 1417-1426)

Más aún, llevando al extremo este juego retórico ${ }^{14}$, para don César en Peor está que estaba, las damas tapadas se vuelven metáfora del sol embozado:

\author{
Ya mi deseo salía \\ a ver, en pardo arrebol, \\ salir rebozado al sol \\ que era para el campo el día. \\ Vengáis a dar alegría, \\ sol disfrazado, a estas flores, \\ que bebiendo resplandores \\ de una luz que no se ve,
}

12 «La noche es capa de pecadores» (Correas, p. 437); «La noche dicen ser capa de pecadores, porque encubre muchos excesos e insultos de los que de día parecen santos» (Cov., s. v.).

13 González ha estudiado cómo en el teatro del Siglo de Oro la palabra es la que transforma el espacio de escenario, en un espacio de ficción; ver «De la palabra a la escena en tres comedias de Calderón", 2006.

${ }^{14}$ Para la utilidad de la retórica en el análisis del teatro, que abarca palabra y representación, ver Azaustre Galiana, «Recursos retóricos en el teatro del Siglo de Oro: el caso de la evidentia», 2009, quien analiza la importancia del espacio textual que se evoca en la imaginación del espectador mediante los parlamentos de los personajes. 
como a su diosa, por fe, os están diciendo amores.

$$
(\mathrm{I}, \mathrm{vv} .626-635)^{15}
$$

Así, el cielo y el sol se humanizan: se visten y se disfrazan, y los galanes y las damas, cuando lo hacen, son soles y cielos cubiertos ${ }^{16}$.

No sólo el ambiente se contagia, en el lenguaje de los personajes hay una conciencia del género que están representando y de la asociación que la comunidad lingüística ha realizado entre la capa y la espada, conexión semántica casi inequívoca; así, por ejemplo, la tradición paremiológica ha sostenido que «defender a capa y espada» se usa "por poner todo su esfuerzo en defendello» ${ }^{17}$, «con todas veras» ${ }^{18}$. En Peor está que estaba, Calderón utiliza, con el caballero, la literalidad, pues efectivamente traen consigo los objetos reales, como lo reitera don Juan: "Yo solo / voy, y con capa y espada / no te receles» (II, vv. 18231825), y, en voz del gracioso, la metáfora, cuando Lisarda le pregunta a Camacho quién es; con la respuesta, el criado se asume como caballero de comedia de capa y espada, aunque se nombre, homenajeando a Sancho Panza, escudero:

CAMACHO

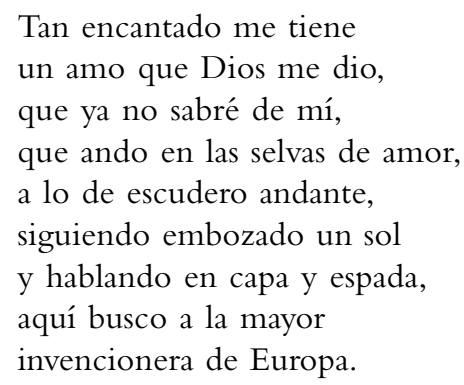

(III, vv. 2159-2171)

Capa y espada comparten la acción del duelo, cuando este sucede de improviso; la primera debe terciarse e incluso revolverse en el bra-

15 Todas las citas a Peor está que estaba corresponden a la edición de Valbuena Briones, 1981.

16 Para los juegos lingüísticos de Calderón, ver Hilder, «Juegos de referencia lingüística en el teatro calderoniano de enredo», 2002.

17 Correas, p. 907.

18 Cov., s. v. 
zo izquierdo para defenderse de los golpes del contrario ${ }^{19}$. Durante la representación de la comedia veremos esta acción en escena; sin embargo, Calderón también la pone en palabras. El manejo de la capa en las riñas será descrito, ya sea en forma cómica, como lo satiriza Moscatel en No hay burlas con el amor:

$\begin{array}{ll}\text { Moscatel } & \text { En la plaza, } \\ \text { un toricantano un día } \\ \text { entró a dar una lanzada } \\ \text { de un su amigo apadrinado. } \\ \text { Y airoso terció la capa, } \\ \text { galán requirió el sombrero, } \\ \text { y osado tomó la lanza } \\ \text { veinte pasos del toril. } \\ {[\ldots] \text {... }} \\ \text { Cayó el caballero encima } \\ \text { del toro, sacó la espada } \\ \text { el tal padrino, y por dar } \\ \text { al toro una cuchillada } \\ \text { a su ahijado se la dio; }\end{array}$

$$
\text { (III, vv. 2059-2085) })^{20}
$$

ya narrando una experiencia personal, como lo hace Lisardo en Casa con dos puertas:

La puerta un hombre entreabrió;

la capa tercié y la espada empuñé, y al mismo instante me volvieron a cerrarla por defuera.

(II, vv. 1703-1709)

19 «Reñir con capa y espada» es «de hombres que no vienen prevenidos para quistión, y revuelven la capa al brazo izquierdo para repararse de los golpes de su contrario» (Cov., s. v.).

${ }^{20}$ Todas las citas a No hay burlas con el amor corresponden a la edición de Arellano, 1981. 
Dejando las capas, pasemos a las espadas, las cuales representan la valentía, la virilidad y la destreza ${ }^{21}$; cualidades que debe poseer el galán de estas comedias. De este modo, el galán (y el actor en consecuencia) debe estar armado casi «de punta en blanco» ${ }^{22}$ y estar siempre listo para acometer. La espada era, como dice Covarrubias: la «común arma de que se usa, y los hombres la traen de ordinario ceñida, para defensa y para ornato y demostración de lo que son; y a los que no están tenidos en esta reputación, les dicen que traen ruecas» ${ }^{23}$. Calderón nos muestra cómo a los nobles, aunque sean detenidos por la justicia no se les desarma por la dignidad que poseen, así a don César en Peor está que estaba:

Gobernador Ya sé quién sois; el acero no os desciñáis, que con él habéis de ir, aunque vais preso.

$$
\text { (I, vv. 820-825) }
$$

${ }^{21}$ Así registrado por Correas: «A quien no le basta espada y corazón, no le bastarán corazas y lanzón» (p. 34).

22 Autoridades: «Armado de punta en blanco: Quiere decir: armado de pies a cabeza, con todas las piezas de un arnés, y las demás armas defensivas y ofensivas desnudas, a punta y guisa de acometer y pelear; éste es el conceto y sentido que todos hacen, y lo que entienden por "armado de punta en blanco". Por qué se dijo, ya lo tiene olvidado el vulgo, y no veo quien lo sepa, que es harta maravilla estando la razón tan a la mano y cerca; por lo que se dijo es: porque cuando un caballero va a entrar en batalla y acometer al enemigo, o en justas y torneos, va todo armado con la lanza en ristre, desnuda la cuchilla, y descubierta en blanco la punta; y si son hombres de a pie, también acometen armados a su modo, con petos y jacos, y las espadas desnudas, y las picas y chuzos, que es "llevar la punta en blanco". Bien notorio es que las espadas de corte, desnudas, se llaman espadas "blancas" porque están acicaladas y lucidas, a diferencia de las de esgrima, que se llaman "negras" porque lo están. Dícese por lo mesmo "esgrimir con espadas blancas" por las de corte: y ansí las lanzas, cuando las llevan en mano desnudas las puntas, van "de punta en blanco", a diferencia de cuando están con sus fundas, o cubiertas, o vainas en la armería, por defensa del polvo y orín. Si un hombre va caminando con un gorguz o azagaya en la mano, cuando pasa por lugar le pone en la punta un zoquete de corcho u otra cosa; y si no, tiene pena si la lleva descubierta, que es "la punta en blanco" propiamente. De más desto, usan en las espadas largas y estoques y montantes, tener cercenado un tercio de la vaina a la parte de la punta para dejarla en casa saliendo de noche, lo cual es "salir de punta en blanco"».

23 Cov., s. $v$. 
Con la espada, «arma peculiar de los españoles, y así le llaman gladius hispaniensis» ${ }^{24}$, se hiere "ordinariamente de punta, como otras naciones de tajo o revés; y así la espada cumplida y de marca ${ }^{25}$ se inventó para esto» ${ }^{26}$; lo sabe bien el gracioso Mosquito de El escondido y la tapada:

MosQuito Dos alguaciles, señora, porfian, a lo que entiendo, por no decir que hacen punta, pues a estocadas me han muerto ${ }^{27}$.

En las comedias de Calderón se usan las espadas blancas ${ }^{28}$ : las aceradas que relucen, lo cual también puede transformarse en descripción poética, como lo hace doña Ángela ante la espada de don Manuel en La dama duende, cuando éste la ataca creyendo atacar al duende:

Doña Ángela ¡Ay de mí!, ¡detén la espada,
sangriento el brazo detén!;
$[\ldots]$
No manches pues, no desdores
con mi sangre el rosicler
de ese acero.

(II, vv. 2145-2159) $)^{29}$

24 Cov., s. $v$.

25 El refranero da cuenta de algunas de las marcas y hace destacar a las valencianas; así en Correas: «Espada de la es, ni la prestes ni la des, ni la tengas más de un mes: Las espadas que tenían por señal la letra S, que llaman en catalán "es", y en castellano "ese", no eran buenas; ni las que se doblan, y quedan hechas S» (p. 348); "Cantarle el salmo de Herlincampus: Reñir a uno y amonestarle. "Herlincampus" es nombre tomada a burla de los escritos en espadas estranjeras» (p. 154); "Espada valenciana y broquel barcelonés; puta toledana y rufián cordobés» (p. 348); «Joanes me fecit. La de "Joanes me fecit": Es escrito en espadas" (p. 981).

26 Cov.

27 Todas las citas de El escondido y la tapada corresponden a la Parte nona de comedias escogidas de los mejores ingenios de España.

28 Espadas blancas: «las aceradas con que nos defendemos y ofendemos, a diferencia de las de esgrima, que son de solo hierro, sin lustre, sin corte y con botón en la punta. A las espadas blancas llamó Lampridio, en la Vida de Cómodo, lucientes» (Cov, s.. v.).

29 Todas las citas a La dama duende corresponden a la edición de Rey Hazas y Sevilla Arroyo, 1989. 
También en La dama duende, tenemos otro tipo de espada: la metafórica espada virgen: «la que siempre ha tenido su dueño en la vaina, y nunca riñó con ella, ni sacó sangre» ${ }^{30}$, como la que porta Cosme, que «es doncella; / y sin cédula o palabra / no puedo sacarla» (I, vv. 178-180). Porque, a diferencia de los caballeros, los criados sí puede dejar un combate, siguiendo aquello de «a fuerza de varón, espada de gorrión: que cuando hay violencia de mayor, se tenga maña y paciencia, y use de blandura y cortesía, con la gorra en la mano» ${ }^{31}$, como vemos hacer a Calabazas en Casa con dos puertas:

Calabazas

FABIO

Calabazas

FABIO

Calabazas
¡Deteneos, por Dios!

¿Quién sois?

Si es que el miedo no me engaña, un curioso impertinente.

Dejad la espada.

\section{La espada}

es poca cosa; el sombrero, la daga, el broquel, la capa, la ropilla y los calzones.

(III, vv. 2846-2852)

Pero, un galán, cuando desenvaina una espada, no puede dejar de luchar, con la excepción de que el movimiento haya sido impulsivo, como reacción ante lo que no puede ver, y luego resulte ser una dama o un criado. La convención del honor es que una vez que se pone la mano en la espada, que es el primer movimiento después de empuñarla y "sacarla un tercio fuera de la vaina» ${ }^{32}$, «se ha de mostrar el hombre valeroso y de ánimo» ${ }^{33}$ y ya no puede no luchar hasta satisfacer su honor. Esta es la teoría, sin embargo, Calderón parece preferir los «duelos» con la palabra, aunque ya se haya desenvainado la espada; como el que se encuentra en El escondido y la tapada, en donde

30 Cov., s. $v$.

31 Correas, p. 14.

32 Cov., s. $v$.

33 «En el árbol de la mano no ha de temblar la hoja, y ha de tener la espada la guarnición del consejo: Antes de echar mano se ha de mirar muy bien, y después de sacada la espada se ha de mostrar el hombre valeroso y de ánimo» (Correas, p. 312). 
don César sale cubierto el rostro con la capa y la espada desenvainada como corresponde:

D. Diego Hombre, que de tanto honor

la reputación agravias,

¿quién eres?

CÉSAR

Un hombre soy.

D. Diego

Quita del rostro la capa.

CÉSAR

No puedo, porque encubierto

sin que me veas la cara

me has de dar muerte aquí

en la defensa bizarra

desta mujer, ella y yo

habemos de aquesta casa

de salir, si con mi muerte

mis intentos no se atajan.

$[\ldots]$

D. JUAN

También lo es

que sea tal tu arrogancia, que pienses que entre nosotros, te has de llevar esa dama, sin que sepamos por qué y cómo en aquesta casa estáis tú, y ella?

CÉSAR No puedo decirlo.

FÉLIX Pues las espadas harán bocas en tu pecho por donde la verdad salga.

(III, pp. 569-570)

Disparan dentro y se interrumpe el duelo que hasta ahora ha sido de palabra. Finalmente don César se descubre y viene el desenlace, en el que sin reñir, todos quedan satisfechos. Pero, mejor aún, Calderón, como maestro de la palabra, prefiere describir los «duelos» a que sucedan en escena ${ }^{34}$. El «duelo», por ejemplo, puede suceder antes de

34 Para los efectos dramáticos de representar las muertes en escena en el teatro del Siglo de Oro, ver Couderc, 2009. 
que comience la obra y ocasionar la trama, como ocurre en El escondido y la tapada; entonces, en la primera escena, don César, quien lo protagonizó, debe describirlo, aunque sea escuetamente:

[...] él mal pensada la respuesta, dijo, más no sé qué dijo, que nunca un noble se acuerda de palabras, que el enojo pronuncia desde la lengua a las espadas, mas luego sacamos los dos las nuestras.

De una estocada cayó en el suelo.

$$
\text { (I, p. 539) }
$$

En Peor está que estaba, donde Calderón utiliza el mismo recurso (la trama es resultado de un "duelo» que no vemos), ahora, se recrea describiendo dicho la riña, pero no en voz del protagonista del mismo, sino en la de una dama testigo, que la convierte en imágenes poéticas para que el espectador la recree:

FLÉRIDA

[...] Él no le responde nada, sino se emboza y se empuña en la espada, y yo que estaba, ni bien viva ni difunta, iba a responder por él, cuando veo que se juntan los dos, y brillando a un tiempo las dos espadas desnudas, se tiran. No así animados cometas el aire cruzan, como estos rayos de acero; pues para que no les suplan el fuego, hicieron los dos que fuego la tierra escupa. Quiso Dios, quiso mi suerte - ya que hubo de ser algunaque al pecho de mi enemigo llegó primero una punta.

(I, vv. 381-402) 
Calderón utiliza este recurso, el de la descripción, aun cuando los enfrentamientos ocurren en escena. La dama duende está enmarcada entre espadas desenvainadas, la primera vez para que den inicio los enredos de la alacena, pues don Manuel al llegar a Madrid haya: «una dama que rogase / que su vida defendiese, / un hermano que le hiriese / y otro que le aposentase» (I, vv. 557-560). Este primer enfrentamiento con espadas, en el que don Manuel es herido en una mano, a pesar de que sí lo vemos, se describe luego, cuando don Luis se lo narra a su hermana:
Llegó en aquella ocasión, en defensa del crïado, nuestro huésped, muy soldado; sacamos, en conclusión, las espadas. Todo es esto, pero más pudiera ser.

(I, vv. 509-515)

La espada en La dama duende se vuelve un instrumento simbólico del caballero mismo, así provocará envidia y admiración: «Él es buen caballero, / y me tiene envidioso de su acero, / de su estilo admirado / y he de ser muy su amigo y su crïado» (I, vv. 665-668), y representará al caballero mismo que se pone a los pies del otro; la espada adquiere así la personalidad de quien la ciñe $e^{35}$.
y porque el instrumento de la herida
en mi poder no quede,
pues ya agradarme ni servirme puede,
bien como aquel criado
que a su señor algún disgusto ha dado,
hoy de mí le despido.
Ésta es, señor, la espada que os ha herido;
a vuestras plantas viene
a pediros perdón, si culpa tiene.

35 Así lo había conceptualizado ya el refranero: «La espada y la sortija, en cuya mano están han valía» (Correas, p. 418); «La sortija y la espada, en cuya mano anda es estimada» (Correas, p. 445). 
Tome vuestra querella

con ella en mí venganza de mí y della.

(I, vv. 672-682)

La aceptación de don Manuel de la espada es la aceptación de la disculpa y el reconocimiento honorable de las virtudes del otro caballero; la espada está investida de valentía y generosidad:

Don Manuel Sois valiente y discreto;

en todo me vencéis. La espada aceto,

porque siempre a mi lado

me enseñe a ser valiente. Confiado

desde hoy vivir procuro;

porque ¿de quién no vivirá seguro

quien vuestro acero ciñe generoso?

Que él solo me tuviera temeroso.

(I, vv. 683-690)

Cuando don Luis descubre la alacena, volverán a las espadas; para don Luis, don Manuel es un traidor y, así, su espada es infame.

DON LuIS

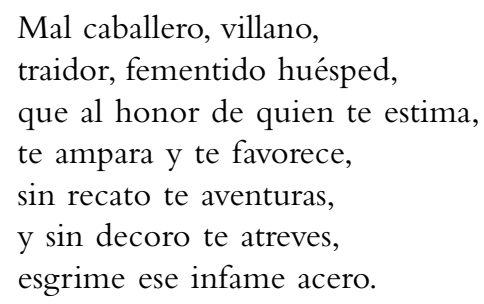

Mal caballero, villano, traidor, fementido huésped, que al honor de quien te estima, te ampara y te favorece, sin recato te aventuras, $\mathrm{y} \sin$ decoro te atreves, esgrime ese infame acero.

(III, vv. 2739-2745)

Don Manuel lo esgrimirá para defenderse, aunque primero pretende dar satisfacciones: «Mil veces / rompa esa espada mi pecho, / Don Luis, si yo eternamente / supe desta puerta, o supe / que paso a otro cuarto tiene» (III, vv. 2768-2772). Pero don Luis está a punto de decirle mentiroso, por lo que don Manuel debe atajarlo, «Y pues ya es fuerza reñir, / riñamos como se debe» (III, vv. 2791-2792); esto es: a muerte: «que con la espada en la mano / sólo ha de vivir quien vence» (III, vv. 2813-2814). Comienza el duelo y aunque lo estamos viendo, los contendientes describen la destreza del otro con palabras: 
Don Manuel ¡No vi más templado pulso!

Desguarnécesele la espada.

DON Luis ¡No vi pujanza más fuerte!

(III, vv. 2835-2836)

Aunque esta riña también la vemos, Calderón vuelve a narrarla en voz de una mujer, doña Ángela, que no la ha visto, sino la ha oído, con lo que el combate y las actitudes de los contrincantes se hacen más interesantes e incluso, con mejor ritmo:

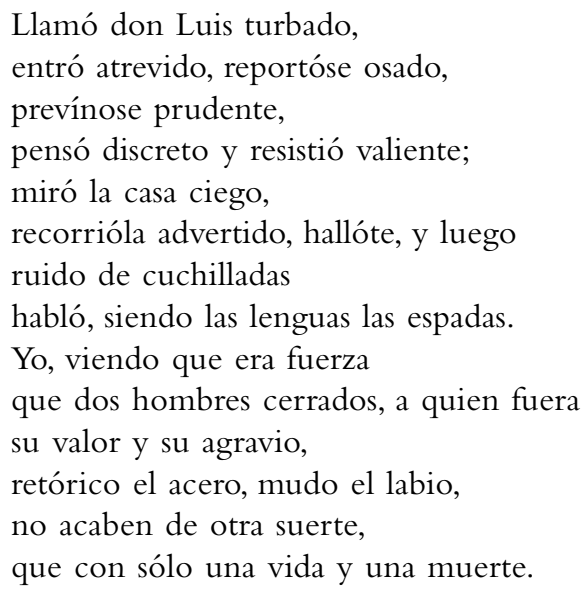

(III, vv. 2911-2924)

El segundón de don Luis es la espada misma que va y viene, que se desenvaina, que hiere, que debe reportarse, que se rinde al huésped, que vuelve a desenvainarse, que se rompe (no por falta de valor, sino por causa de la fortuna, tan en contra de don Luis), que se remplaza, que quiere volver a postrarse, pero debe de nuevo esgrimirse por el honor y detenerse otra vez, pues, como puntualiza don Manuel, honor y espada son equivalentes: "pues / en quien sustenta su fama / espada y honor han sido / armas de más importancia, / dejadme ir vos por honor, / pues yo os dejé ir por espada» (III, vv. 3059-3066); finalmente, al ofrecer don Manuel la mano a doña Ángela, la tercera espada de don Luis y don Luis quedan satisfechos.

En No hay burlas con el amor, la espada se vuelve aún más un elemento poético. Tras saltar don Alonso por el balcón termina la se- 
gunda jornada, al inicio de la tercera don Juan contará lo que sucedió después: oyó cuchilladas y cuando llegó, don Alonso estaba herido. El desenamorado y cuestionable galán de comedia don Alonso, ahora está melancólico, y Mosca, su criado, le pregunta: «¿Qué mudanza / es aquésta? ¿Tan válida / ha sido una cuchillada / contigo? ¿Tanto consigue / una herida?» (III, vv. 2031-2035). Cuchillada que hace que Inés le envíe una banda y que se provoquen celos. La espada formará parte de la conclusión inevitable a la que llega don Alonso en la obra, aquel para quien todo era burlas, todo se vuelve veras, y la espada forma parte de las metáforas que describen este caso:

Tal vez desnuda un amigo

la espada para esgrimir con otro, y le viene a herir como si fuera enemigo. $\mathrm{Su}$ destreza es su castigo, y así, usar della es error. Espada amor en rigor es: luego, desenvainada, si no hay burlas con la espada, no hay burlas con el amor. [...]

Por burla al mar me entregué, por burla el rayo encendí, con blanca espada esgrimí, con brava fiera jugué, y así, en el mar me anegué, del rayo sentí el ardor, de acero y fiera el furor: luego, si saben matar, fiera, acero, rayo y mar, no hay burlas con el amor.

(III, vv. 2605-2634) ${ }^{36}$

36 Si las «las burlas del buen gusto / son las veras del acero» (No hay burlas, I, vv. 319-322), también para los personajes graves esgrimir la espada es muestra del honor, como lo expresa don Diego en El escondido y la tapada: «y a no poder con razones / podré con la espada, que este / pecho volcán es, que ostenta / dentro fuego y fuera nieve». 
Otras armas filosas aparecen en las comedias de capa y espada como dagas y flechas. Las dagas las pide Calderón para matar hermanas, así dice don Félix en Casa con dos puertas: "Corrido estoy; esta daga / dé a una vil hermana muerte» (III, vv. 3021-3022); o para abrir puertas, como intenta don César en El escondido y la tapada: "Desclavar pretendo / con esta daga la puerta / y salir de aquí primero / que mi enemigo me cierre / hoy el paso» (II).

Las flechas únicamente las utiliza Amor, por lo que estas son las armas por excelencia para no ser vistas, sino descritas, así como su tiro, su vuelo y sus heridas, como lo siente don Félix en Casa con dos puertas:

$¡ \mathrm{O}$ hubiera sido su golpe, puesto que a todos alcance, por costumbre solamente flecha disparada al aire, y no por venganza flecha bañada en venenos tales, que salió del arco pluma, corrió por el viento ave, llegó rayo al corazón, donde se alimenta áspid! La primera vez que sentí este golpe penetrante, —que sabe herir sin matar, $\mathrm{y}$ aun esto es lo más que sabe-

(I, vv. 242-268)

O don Juan en Peor está que estaba:

Turbado llegó, ciego a su amor, como a sus rayos ciego.

Si merece favor tan soberano quien al dosel de tanto sol se atreve, dadme, señora, vuestra blanca mano, aljaba a quien Amor sus flechas debe; porque siendo un prodigio más que humano, un monstruo celestial de fuego y nieve, centro de los dos sois, donde amor ciego abrasa con cristal, hiela con fuego.

(II, vv. 1206-1215) 
Las flechas y las heridas de amor son descritas por los galanes más que por las damas, ellas prefieren narrar los enfrentamientos de sus caballeros con la espada; también ellas suelen ser las artífices de los enredos, por lo que con bien andan las comedias donde de la rueca manda a la espada y donde nuestros galanes simbólicamente, en algún momento, se debaten "entre la espada y la pared», pues suelen estar en la encrucijada del honor, la amistad, la defensa de la mujer, y los demás códigos, así, en El escondido y la tapada, don Juan: "Qué debo yo hacer aquí / en tan fiera, en tan tirana / ocasión como me ví? / Celia, de Félix hermana, / viene a valerse de mí; / Félix, buscando a un traidor, / para alentar con valor / su venganza, y mi venganza, / puso en mí la confianza / de su vida y de su honor» (III, p. 567).

De este modo, contagiado el mundo poético y dramático de capas y espadas, en estas comedias, Calderón, además de tomar los tópicos y convenciones del género, los sublima al convertirlos en palabra, pues si suceden antes de que inicie la comedia (sólo en estos casos hay muerte, por lo menos en las comedias analizadas), son narrados escuetamente por los protagonistas o ampliamente por testigos femeninos; e incluso, si suceden en escena, Calderón hace que sucedan de nuevo a través de imágenes y conforma con ellos sobre el acto escénico un acto poético.

Si los caballeros dejan palabras y razones, si, como dice doña Ángela, suena "retórico el acero, mudo el labio», Calderón con la capa terciada y la pluma desenvainada hace sonido y palabras a las capas, las espadas y los duelos para el deleite del oído. 


\section{BibLIOgRAFÍA}

Arellano, I., Convención y recepción. Estudios sobre el teatro del Siglo de Oro. Madrid, Gredos, 1999.

Azaustre Galiana, A., "Recursos retóricos en el teatro del Siglo de Oro: el caso de la evidentia», en El teatro del siglo de Oro. Edición e interpretación, ed. A. Blecua, I. Arellano y G. Serés, Madrid / Frankfurt, Iberoamericana / Vervuert, 2009, pp. 29-50.

Calderón de la Barca, P., Casa con dos puertas, mala es de guardar, ed. A. Rey Hazas y F. Sevilla Arroyo, Barcelona, Planeta, 1989.

— «El escondido y la tapada», Parte nona de comedias escogidas de los mejores ingenios de España, Madrid, Gregorio Rodríguez, a costa de Mateo de Bastida, 1657, ed. Facsímil, Alicante, Biblioteca Virtual Miguel de Cervantes, Madrid, Biblioteca Nacional, 2010.

- El postrer duelo de España, ed. G. Rossetti, London, Tamesis, 1977.

- La dama duende, ed, A. Rey Hazas y F. Sevilla Arroyo, Barcelona, Planeta, 1989.

- No hay burlas con el amor, ed. I. Arellano, Pamplona, Eunsa, 1981.

- Obras Maestras, coords. J. Alcalá-Zamora y J. M. ${ }^{a}$ Díez Borque, Madrid, Castalia / España Nuevo Milenio, 2000.

- Peor está que estaba, ed. Á. Valbuena Briones, Madrid, CSIC, 1981.

Correas, G., Vocabulario de refranes y frases proverbiales (1627), ed. L. Combet, Madrid, Castalia, 2000.

Couderc, C., «El cadáver en escena en el teatro de Lope de Vega», en El teatro del siglo de Oro. Edición e interpretación, ed. A. Blecua, I. Arellano y G. Serés, Madrid / Frankfurt, Iberoamericana / Vervuert, 2009, pp. 51-77. Covarrubias, S. de, Tesoro de la lengua castellana o española [1611], ed. F. C.R. Maldonado, revisado por M. Camarero, Madrid, Castalia, 1995.

Forastieri-Braschi, E., "Secuencias de capa y espada: escondidos y tapadas en Casa con dos puertas», en Calderón. Actas del Congreso Internacional sobre Calderón y el teatro español del Siglo de Oro, 1981, ed. L. García Lorenzo, Madrid, CSIC, 1983, vol. I, pp. 433-449.

GonzÁLEZ, A., "De la palabra a la escena en tres comedias de Calderón», en La Dramaturgia de Calderón. Técnicas y estructuras, ed. I. Arellano y E. Cancelliere, Madrid / Frankfurt, Iberoamericana / Vervuert, 2006, pp. 229-248. HiLDNER, D. J., «Juegos de referencia lingüística en el teatro calderoniano de enredo", en Calderón entre veras y burlas. Actas de las II y III jornadas de Teatro Clásico de la Universidad de la Rioja, 2000, ed. F. Domínguez Matito y J. Bravo Vega, Logroño, Universidad de la Rioja, 2002, pp. 177-188. 